\title{
Long-term outcomes of major upper extremity replantations
}

\author{
Wendy KY Ng MD ${ }^{1}$, Manraj Nirmal Kaur PT MSc ${ }^{1,2}$, Achilleas Thoma MD MSc FRCSC FACS ${ }^{1,2,3}$
}

WKY Ng, MN Kaur, A Thoma. Long-term outcomes of major upper extremity replantations. Plast Surg 2014;22(1):9-13.

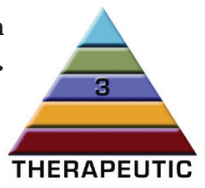

BACKGROUND: Long-term outcomes of major upper extremity replantations are infrequently reported. It is believed that replantation is indicated for amputations at all levels in children and for all distal amputations in adults. Replantations of arm or proximal forearm amputations in adults are controversial.

OBJECTIVE: To evaluate the results of major upper extremity replantations, defined as those that are transmetacarpal, through the wrist, forearm, elbow or arm.

METHODS: A review of these types of replantations performed at the authors' institution from 2002 to 2012 was conducted. Patients' strength, range of motion and two-point discrimination were assessed. Patients completed the Disabilities of the Arm, Shoulder and Hand (DASH), the Michigan Hand Questionnaire (MHQ), and the Hospital Anxiety and Depression scale (HADS).

RESULTS: Seventeen patients underwent major upper extremity replantation surgery. The majority (16 of 17 [94\%]) of the included patients were male. Of 17 patients, $13(76.5 \%)$ required reoperations. The mean ( \pm SD) DASH score of seven patients who consented to completing all questionnaires was $75.4 \pm 14.2$ of 100 (range 59.2 to 91.1). On the MHQ, the mean score for affected hand function was $16 \%$ compared with $84 \%$ in the unaffected hand. Patients generally demonstrated at least mild levels of anxiety and depression on the HADS.

DISCUSSION: The results suggest that major upper extremity injuries and replantations have a significant impact on patients' long-term hand function, and produce long-term anxiety and depressive symptoms.

Key Words: Functional outcomes; Microsurgery; Quality of life; Replantation; Upper extremity

Tpper extremity replantation, first performed by Dr Ronald Malt in Boston in 1962, is now widely used to manage patients with sharp, guillotine-type, minimally contaminated amputations of the thumb, multiple digits, hand, wrist and forearm $(1,2)$.

Survival of the replanted extremity is the most common parameter for which the success or failure of this procedure has been evaluated. It has been reported to be between $80 \%$ and $94 \%(3,4)$. However, this outcome measure only indicates that the replanted limb is viable at the follow-up visit. More useful outcome measures are those assessing the functional outcome of the surgery such as Chen's criteria, the ability to resume work, range of motion relative to normal, sensibility and power (4). Ideal assessments are those that include patient-reported quality of life as well as functional outcomes. These offer a better indication of success or failure of replantation.

Physiological outcomes measured by clinicians provide valuable information regarding patient recovery status even if there is a threat of introducing bias. For example, a viable replanted arm may be considered a success from the point of view of the surgeon; however, if the patient is unable to perform most of his or her activities of daily living (ADL) and depends on social assistance, the procedure may be considered a failure.

\section{Les issues à long terme de réimplantations majeures des membres supérieurs}

HISTORIQUE : On rend rarement compte des issues à long terme des
réimplantations majeures des membres supérieurs. On croit que la réim-
plantation est indiquée pour tout type d'amputation chez les enfants et
pour toute amputation distale chez les adultes. Chez les adultes, la réim-
plantation d'un bras ou de la partie proximale d'un avant-bras amputé est
controversée. OBJECTIF : Évaluer les résultats de réimplantations majeures des membres supérieurs, définies comme des réimplantations transmétacarpiennes, à partir du poignet, de l'avant-bras, du coude ou du bras.

MÉTHODOLOGIE : Les auteurs ont analysé ce type de réimplantations effectuées au sein de leur établissement entre 2002 et 2012. Ils ont évalué la force, l'amplitude de mouvement et la discrimination en deux points des patients. Ceux-ci ont rempli le questionnaire DASH sur l'invalidité du bras, de l'épaule et de la main, le questionnaire Michigan de la main (MHQ) et l'échelle HADS d'anxiété et de dépression en milieu hospitalier. RÉSULTATS : Dix-sept patients ont subi une réimplantation majeure d'un membre supérieur. La majorité d'entre eux (16 sur 17 [94 \%]) étaient de sexe masculin. Sur les 17 patients, 13 (76,5 \%) ont dû être réopérés. L'indice DASH moyen $( \pm E ́ T)$ des sept patients qui ont consenti à remplir tous les questionnaires était de 75,4 $\pm 14,2$ sur 100 (plage de 59,2 à 91,1). Au MHQ, l'indice moyen de la fonction de la main touchée s'élevait à $16 \%$ par rapport à $84 \%$ dans la main non touchée. En général, les patients présentaient au moins un taux moyen d'anxiété et de dépression selon l'échelle HADS.

EXPOSÉ : Selon les résultats, les blessures et les réimplantations majeures des membres supérieurs ont des conséquences importantes sur la fonction à long terme de la main des patients et entraînent des symptômes d'anxiété et de dépression à long terme.

Given that major upper extremity replantations have been performed and reported for more than three decades (4-6), it is surprising that these outcomes have never been measured using patient-reported outcome measures.

Amputation is a disfiguring event (7) that causes substantial psychological, social, vocational and financial suffering for the patient. Hence, it is imperative that the patient remain the focus of the assessment of the outcome of replantation surgery. Patient-reported outcome measures are increasingly used to assess patients' experience with illness and disability (8). They signify the benefit/loss from surgery as perceived by the patient, and are useful for pre- and postoperative patient counselling. Furthermore, they are used as benchmarks of the efficacy of a treatment and for determining the allocation of health care resources.

The aim of the present study was to assess the long-term outcomes of major upper extremity replantation using both objective and patient-reported outcome measures. Major upper extremity amputations are defined as those at the level of metacarpal, wrist, forearm, elbow or arm (9). We believe that the results of the present study add to the major upper extremity replantation literature and emphasize the advantages of patient-reported outcome measures in assessing surgical outcomes.

${ }^{1}$ Division of Plastic Surgery; ${ }^{2}$ Surgical Outcomes Research Centre, Department of Surgery; ${ }^{3}$ Department of Clinical Epidemiology and Biostatistics,

Faculty of Health Sciences, McMaster University, Hamilton, Ontario

Correspondence: Dr Achilleas Thoma, Division of Plastic Surgery, Department of Surgery, McMaster University, Hamilton, Ontario L8P 3A9.

Telephone 905-523-0019,fax 905-523-0229,e-mail athoma@mcmaster.ca 
TABLE 1

Characteristics of patients undergoing major upper extremity replantations

\begin{tabular}{llllll}
\hline Patient & $\begin{array}{c}\text { Age at injury, } \\
\text { years }\end{array}$ & Sex & Occupation & Injury mechanism & $\begin{array}{c}\text { Duration of } \\
\text { Level of amputation } \\
\text { follow-up, years }\end{array}$ \\
\hline 1 & 60 & Male & Crane operator & Table saw & Metacarpal \\
2 & 39 & Male & Carpenter & Self-inflicted after argument & Metacarpal \\
3 & 42 & Male & Construction worker & Wood speed saw & Metacarpal \\
4 & 39 & Male & Welder & Industrial drill & Metacarpal \\
5 & 48 & Male & Cabinet maker & Self-inflicted after argument & Forearm \\
6 & 40 & Male & Meat processing plant worker & Processing machine & Wrist \\
7 & 51 & Male & Farmer/sawmill worker & Saw & Metacarpal \\
8 & 57 & Female & Industry worker & Industrial saw & Forearm \\
9 & 43 & Male & Not mentioned & Mixer at work & Wrist \\
10 & 47 & Male & Truck driver & Rotary saw & Metacarpal \\
11 & 23 & Male & Student & Self-inflicted after argument & Wrist \\
12 & 56 & Male & Not mentioned & Circular saw & Metacarpal \\
13 & 68 & Male & Factory worker & Saw & Forearm \\
14 & 54 & Male & Not mentioned & Self inflicted after argument & Wrist \\
15 & 14 & Male & Student & Shear saw & Wrist \\
16 & 44 & Male & Not mentioned & Self inflicted & Wrist \\
17 & 49 & Male & Roofer & Mitre saw & Metacarpal
\end{tabular}

\section{METHODS}

A retrospective chart review of all major upper extremity replantations performed at the three McMaster University-affiliated hospital sites (Hamilton General Hospital, St Joseph's Healthcare Hamilton and McMaster University Medical Centre), in Hamilton, Ontario from 2002 to 2012 was undertaken. All patients with amputations at the level of metacarpals, wrist, forearm, elbow or arm who underwent replantation surgery were included. Patients with digital replantation were excluded.

Demographic information including patient age, occupation, hand dominance, mechanism of injury, medical history, concomitant injuries, in-hospital services required, subsequent operations (if any), complications and last follow-up appointment were recorded.

A minimum of three attempts were made to contact the included patients by the study investigator (WN) or by medical administrative assistants of each surgeon's offices via telephone. Objectives of the study were explained to the patients and informed consent was obtained. The study was approved by the Hamilton Integrated Research Ethics Board, Hamilton, Ontario. These patients were invited to return for a clinic visit.

\section{Objective measures}

In this follow-up visit, grip and strength measurements were undertaken using a JAMAR dynamometer (Sammons Preston, USA) and a key pinch device, respectively, by the study investigator (WN). Active range of motion was measured using a two-arm goniometer. Dynamic two-point discrimination was evaluated using a Padgett two-point discriminator and recorded in millimetres. All assessments were performed twice bilaterally (on both the affected and nonaffected extremities) and the best effort from the two trials was recorded for analysis. All of these measurements were performed by the first author (WN).

\section{Patient-reported outcome measures}

At their follow-up visits, the patients completed a battery of three selfreport questionnaires: Disabilities of the Arm, Shoulder and Hand (DASH) (10,11); the Michigan Hand Questionnaire (MHQ) (12-16); and the Hospital Anxiety and Depression scale (HADS) (17-20). The $\mathrm{DASH}$ and MHQ were chosen because they are the most frequently used patient-reported outcome measures in hand surgery. Meanwhile, the DASH questionnaire includes a 30 -item scale relating to upper extremity function. It is scored as a percentage ( 0 indicates no problems). These scales have been validated in the evaluation of impairments, activity limitations and participation restrictions to normal ADL. The
MHQ consists of 37 hand-specific questions, divided into the following domains: overall hand function; ADL; pain; work performance; aesthetics; and patient satisfaction with hand functioning $(12,14,15)$.

The HADS was chosen because it offers a psychological perspective on patients' well being. It is considered to be a good screening tool for identifying comorbid anxiety and depressive disorders in patients with musculoskeletal disorders (19). The HADS is a self-administered measure used to screen for the presence of depression and anxiety. The HADS was developed to provide clinicians with an acceptable, reliable, valid and easy to use practical tool for identifying and quantifying depression and anxiety. Although the HADS scale cannot be used for clinical diagnoses, raw scores of between 8 and 10 identify mild cases, 11 to 15 moderate cases and $\geq 16$ severe cases (20).

Patient characteristics

\section{RESULTS}

Between 2002 and 2012, 17 patients underwent major upper extremity replantation surgery at the hospital centres (Hamilton General Hospital, St Joseph's Healthcare Hamilton and McMaster University Medical Centre). All patients underwent replantation under general anesthesia with tourniquet control where possible, using a standard replantation sequence starting with bony stabilization (5). No arterial shunting was used in any of these cases.

The majority (16 of 17 [94.1\%]) of the included patients were male. Ten of $17(50.8 \%)$ patients were manual labourers employed in construction or manufacturing factories, two (11.8\%) were students, one $(5.9 \%)$ was a truck driver and the remaining four $(23.5 \%)$ did not specify their vocation. The mean $( \pm \mathrm{SD})$ age of the patients at the time of injury was $45.5 \pm 13.0$ years (range 14 to 68 years). The amputation level was at the metacarpals in eight $(47.1 \%)$ patients, at the wrist in six $(35.3 \%)$ and the forearm in three $(17.7 \%)$. Of the 17 patients, $13(76.5 \%)$ required reoperations, including five revision amputations over an average follow-up period of four years (range one to 10 years).

One-quarter $(n=4)$ of these patients experienced self-inflicted injuries. Three of these four patients had known significant psychiatric histories, including depression, bipolar disorder, history of alcohol and drug abuse or overdose, and anxiety. One of these four patients had reported previously being seen by a psychiatrist, but had no identified psychiatric diagnoses and was not on any psychiatric medications. Other patients sustained injuries in accidents or when using machinery at work (Table 1).

In 10 of 12 patients, the affected upper extremity involved the dominant hand. Hand dominance could not be determined for two patients because this information was not recorded in the hospital 


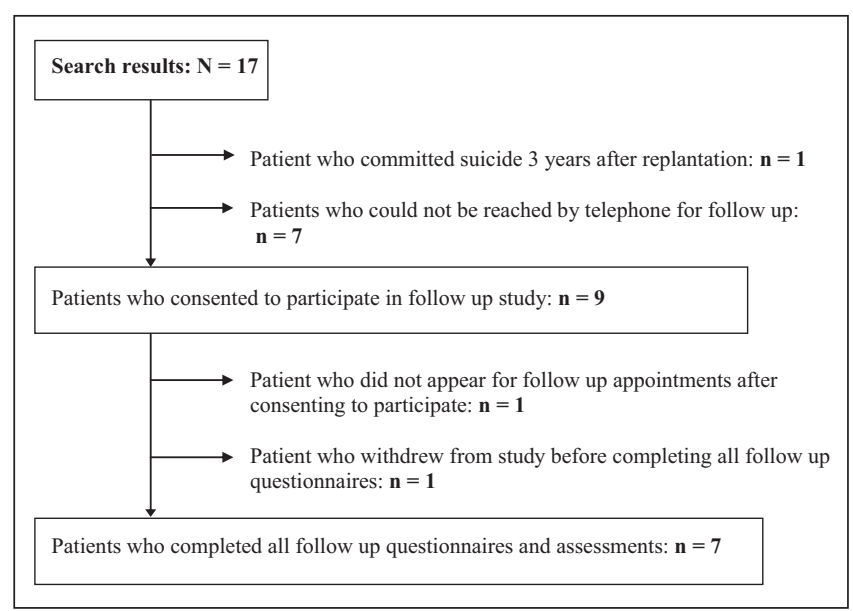

Figure 1) Flow diagram of patient inclusion

record on admission or in follow-up notes; these two patients could not be contacted for follow-up or did not present to any hand therapy appointments. The mean length of initial hospital stay was 12.1 days (range four to 30 days).

Thirteen of 17 patients required subsequent operations including debridement, skin grafting, removal of hardware, tenolysis, tendon transfer, manipulation under anesthesia or evacuation of thrombosis $48 \mathrm{~h}$ after initial replantation. Five patients underwent partial or revisional amputation at a later date for nonfunctioning extremities. No patients required further immediate subsequent operations for reestablishment of circulation. For patients who required subsequent operations, the median number of subsequent operations under general anesthesia was 1 (range 1 to 4 ). Other than the plastic surgery service, other services involved in the care of patients while in hospital during initial admission included orthopedic surgery, nursing, psychiatry, geriatrics, occupational and physiotherapy, social work, home care and nutrition. One patient received treatment with hyperbaric oxygen while in hospital.

\section{Long-term outcomes following replantations}

One of 17 patients committed suicide three years after his replantation. Before his injury, he had no psychiatric diagnoses. Of the 16 remaining patients, one did not attend his follow-up appointment, while seven could not be reached (their telephone numbers were not operational). One patient who did not attend his follow-up appointment consented to participating on the telephone, but did not attend his follow-up appointment. An attempt to reach him by telephone proved unsuccessful after three attempts and he was excluded from the study. Subsequently, eight patients were willing to participate in a follow-up assessment. The mean length of follow-up for these eight patients was 5.6 years (range two to 10 years) (Figure 1 ).

\section{Employment and educational status}

Only one of eight patients returned to work and reported earning up to $\$ 30,000$ per annum as a truck driver two years after his injury. His preinjury occupations were truck driver and labourer. The remaining patients continued on disability and social assistance programs for the entire duration of follow-up. Additionally, the highest level of education at their follow-up visit was some college in $14.29 \%$ and high school or less than high school in $42.86 \%$.

\section{Objective measures}

The mean grip strength of the injured extremity as measured using a dynamometer was $5.13 \pm 8.54 \mathrm{~kg}$ (range $0 \mathrm{~kg}$ to $25 \mathrm{~kg}$ ) compared with $40.8 \pm 15.66 \mathrm{~kg}$ (range $10 \mathrm{~kg}$ to $60 \mathrm{~kg}$ ) on the uninjured side. Mean key pinch strength on the injured extremity was $4.5 \pm 3.05 \mathrm{~kg}$ (range $0 \mathrm{~kg}$ to $9.8 \mathrm{~kg}$ compared with $13.1 \pm 7.19 \mathrm{~kg}$ (range $4 \mathrm{~kg}$ to $25 \mathrm{~kg}$ ) on the uninjured side (Table 2). The mean moving two-point discrimination,
TABLE 2

\begin{tabular}{|c|c|c|c|}
\hline Patient & $\begin{array}{c}\text { Age at injury, } \\
\text { years }\end{array}$ & $\begin{array}{c}\text { Grip strength, } \mathbf{k g} \\
\text { (\% of uninjured side) }\end{array}$ & $\begin{array}{l}\text { Pinch strength, } \mathbf{k g} \\
\text { (\% of uninjured side) }\end{array}$ \\
\hline 4 & 39 & $25(71.4)$ & $4(47.1)$ \\
\hline 6 & 40 & $0(0)$ & $0(0)$ \\
\hline 7 & 51 & $0(0)$ & $3(15.0)$ \\
\hline 8 & 57 & $0(0)$ & $3.5(87.5)$ \\
\hline 9 & 43 & $0(0)$ & Not applicable \\
\hline 10 & 47 & $8(16.0)$ & $2(19.0)$ \\
\hline 14 & 54 & $4(13.3)$ & $9.8(98)$ \\
\hline 17 & 49 & $4(8.5)$ & $2.5(10)$ \\
\hline
\end{tabular}

as measured using a two-point discriminator, was $7 \mathrm{~mm}$ (range $5 \mathrm{~mm}$ to $9 \mathrm{~mm}$ ) in the affected digits for all patients.

\section{Patient-reported outcome measures}

Seven of eight patients completed all follow-up questionnaires. Two of these seven patients had not undergone any subsequent revision or partial amputation surgeries. The mean DASH score of seven patients was $75.4 \pm 14.2$ of 100 (range 59.2 to 91.1) (Table 3).

On the MHQ, the mean score for affected hand function was $16 \%$ compared with $84 \%$ in the unaffected hand. A higher score indicates more pain on the pain scale of the MHQ. Otherwise, higher scores indicate better hand performance in the other five scales (overall hand function, ADL, work performance, aesthetics, patient satisfaction with hand function) of the MHQ. Ability to perform ADL with the affected hand was $3 \%$ compared with $99 \%$ in the unaffected hand; ability to perform ADL with both hands was 30\%; and ability to perform work with both hands was $29 \%$. The average overall ADL score was $16.2 \%$. Average pain scores for the hand were $46 \%$. This score is out of a possible $100 \%$, in which $0 \%$ would indicate the complete absence of pain in the hand. Mean aesthetics scores for the affected hand were $43.8 \%$; mean satisfaction for the affected hand was $23.6 \%$. These scores are percentage scores out of a possible $100 \%$ for perfect hand function.

Patients demonstrated at least mild levels of anxiety and depression, as measured by the HADS. One of these patients was known to have bipolar disorder before his self-inflicted injury, but the other patients had no previous known psychiatric conditions. Mean HADS anxiety scores were 10.7 (range 0 to 19) of a total score of 21. Average HADS depression scores were 9.6 (range 0 to 17) of a total score of 21, suggestive of mild cases of anxiety and depression (17) (Table 4).

\section{DISCUSSION}

Previous reports describing upper extremity replantations and revascularizations have shown that functional results in using replanted upper extremities, as subjectively reported by patients and through nonstandardized observation, have been reasonably consistent (between $88 \%$ and 94\%) (21-24). In these studies, however, assessment and inclusion criteria varied and the follow-up duration was short. Most of the studies that reported on the outcomes following upper extremity replantations have used objective or surgeon-reported criteria such as Chen's criteria, range of motion, grip strength and sensitivity. However, these measures alone divulge only partial information about the functional status of the patient. In the present study, we report on long-term outcomes of upper extremity replantations using both objective and patient-reported (ie, DASH, MHQ and HADS) measures. Additionally, we decided to focus on major replantation instead of digital replantations because the latter are relatively common and have already been well documented. Finally, no Canadian study to date has has reported on long-term major replantation outcomes.

The results of our study indicate that even after follow-up of four years (range one to 10 years), patients continued to experience significant reduction in range of motion (reduced by $59.4 \%$ for the mean 
TABLE 3

Functional and psychological outcomes of patients undergoing major upper extremity replantations

\begin{tabular}{|c|c|c|c|c|c|}
\hline Patient & Age at injury, years & $\begin{array}{c}\text { DASH score } \\
(0=\text { no disability })\end{array}$ & $\begin{array}{c}\text { Overall activities of daily } \\
\text { living score on } \mathrm{MHQ}, \% \\
(100 \%=\text { normal })\end{array}$ & $\begin{array}{l}\text { HADS anxiety raw score } \\
\quad(0=\text { no anxiety })\end{array}$ & $\begin{array}{c}\text { HADS depression raw score } \\
(0=\text { no depression })\end{array}$ \\
\hline 6 & 40 & 88.33 & 7.14 & 19 & 17 \\
\hline 8 & 57 & 65 & 24.64 & 10 & 8 \\
\hline 9 & 43 & 60.83 & 16.07 & 0 & 0 \\
\hline 10 & 47 & 59.2 & 33.57 & 16 & 10 \\
\hline
\end{tabular}

DASH Disabilities of the Arm, Shoulder and Hand questionnnaire; HADS Hospital Anxiety and Depression scale; MHQ Michigan Hand Questionnaire

TABLE 4

Hospital Anxiety and Depression scale (HADS) scores as percentiles compared with a normative population

\begin{tabular}{|c|c|c|c|c|c|}
\hline Patient & Age at injury, years & $\begin{array}{l}\text { HADS anxiety raw score } \\
\quad(0=\text { no anxiety })\end{array}$ & $\begin{array}{c}\text { Anxiety percentile rank } \\
\text { compared with normative } \\
\text { population }\end{array}$ & $\begin{array}{l}\text { HADS depression raw score } \\
\quad(0=\text { no depression })\end{array}$ & $\begin{array}{c}\text { Depression percentile rank } \\
\text { compared with normative } \\
\text { population }\end{array}$ \\
\hline 6 & 40 & 19 & 99.9 & 17 & 99.8 \\
\hline 7 & 51 & 10 & 88 & 12 & 98 \\
\hline 8 & 57 & 10 & 78 & 8 & 88 \\
\hline 9 & 43 & 0 & 2 & 0 & 5 \\
\hline 10 & 47 & 16 & 99 & 10 & 96 \\
\hline 14 & 54 & 1 & 8 & 5 & 73 \\
\hline 17 & 49 & 19 & 99.9 & 15 & 99.5 \\
\hline
\end{tabular}

total active range of motion for the best digits in the replanted extremity compared with the nonaffected extremity) and in grip strength (reduced by $87.4 \%$ compared with the nonaffected extremity). It should be noted that the best digital dynamic two-point discrimination was good (mean $7 \mathrm{~mm}$; range $5 \mathrm{~mm}$ to $9 \mathrm{~mm}$ ). The patients, as gauged by HADS, were found to experience mild depressive and anxiety symptoms. Unfortunately, due to the nature of the study design, we were unable to obtain the baseline status (ie, immediate postoperative) of the included patients. This prevented us from reporting on the relative improvement from the baseline; however, previous related studies have demonstrated similar results. Previous studies investigating major upper extremity replantation patients show a mean decrease in grip strength of $66 \%$ to $67 \%$, which is fairly consistent with our findings $(4,9)$. Similar to previous studies, few patients return to their pre-injury occupations (9).

Similarly, for patient-reported outcome measures, we chose the MHQ (condition specific) and DASH (region specific) questionnaires because they have been found to be both reliable and valid in patients with upper extremity pathology. The MHQ and DASH are also the most commonly used measures and, hence, facilitate comparison of results across different studies. In previous reports, mean DASH scores of patients who have sustained a major unilateral upper extremity amputation range from 22.1 to $39(25,26)$. As one may expect, mean DASH scores of patients with other upper extremity disorders, such as tennis elbow, carpometacarpal joint arthritis and Dupuytren's, tend to be much lower (10). All of these values are lower than the mean score of 75.4 found in our patient population who underwent major unilateral upper extremity replantations, indicating comparatively significant functional restriction in our patient group. This supports the suggestion that replantation continues to result in major upper extremity dysfunction and limitations long after the initial time of injury and salvage.

We are not aware of any studies in the literature that have reported on outcomes of upper extremity replantations using the MHQ; hence, no direct comparisons can be made. Previous studies have used the MHQ to assess patients with rheumatoid arthritis undergoing silicone metacarpophalangeal joint arthroplasty, with baseline mean ADL scores of $36.6 \pm 27.4 \%$. In comparison, as expected, the mean ADL score of patients after major upper extremity replantations in our study was much lower $(16.2 \pm 12.1 \%)$. Our study offers a glimpse into the relatively limited function that patients reportedly gain after these traumatic, life-changing injuries, even when compared with patients who have already experienced hand pathology requiring surgery, such as those with rheumatoid arthritis (16).

The HADS is a patient-reported measure that aids in identifying depression and/or anxiety. It is easy to administer, and is reliable and valid. While the HADS cannot be used for clinical diagnoses, raw scores of between 8 and 10 suggest mild, 11 to 15 moderate, and $\geq 16$ severe cases of anxiety and/or depression (20). Our study was the first to date to use this scale in evaluating major upper extremity replantation patients. Compared with our values, mean normative population values for anxiety are $6.14 \pm 3.76($ median $=6)$; for depression, $3.68 \pm 3.07$ (median $=$ 3 ); and for the total scale $9.82 \pm 5.98$ (median $=9$ ). It should be noted that normative values are positively skewed and that percentile tables are more useful in interpreting scores for individual patients. Our study population achieved a greatly varied range of scores on both scales, indicating no unidirectional relationship between replantations and the mental status of the patient.

Certain characteristics of our study population may have influenced the results. Our patient population tended to be slightly older (mean age 45 years) than the age reported in literature (24 to 36 years) $(4,9,27-29)$. It has been reported that patients may be less likely to undergo replantation if they are self-pay, older age and at nonteaching hospitals (27). These factors did not play a role in our Canadian study because all patients are covered by universal health coverage, such that the payment status of patients should not influence the decision to replant.

Given that the vast majority of our patients required subsequent operations under general anesthesia, our results support the literature in suggesting that patients should be advised that multiple surgical procedures may be necessary when the decision to replant has been made $(28,30)$. Considering all factors, unpredictable hospital stays and the variability of functional results have led to guarded optimism (31), although many authors continue to suggest that major upper extremity 
replantations are worthwhile $(9,29,32)$. Further inquiry into the impact on health-related quality of life and the cost effectiveness of major upper extremity replantation will offer further insight into the overall effectiveness of these procedures (33).

The results of the present study are based on a retrospective cohort and are, therefore, limited by the study design. We were constrained by the information that was recorded in the patients' charts at the time of replantation and the reliability of this information could not be verified. Morever, we had little to no understanding of certain patient characteristics at the time of injury (eg, sociodemographics, Workplace Safety and Insurance Board status, education and income level). Under ideal circumstances, we would have liked to follow a complete trajectory of the patients undergoing upper extremity replantation (ie, preoperative, immediate postoperative and follow-up visits at regular time intervals) to ascertain the effectiveness of the procedure. However, because major replantations are relatively rare, this would

\section{REFERENCES}

1. Silverman PM, Willette-Green V, Petrilli J. Early protective motion in digital revascularization and replantation. J Hand Ther 1989;2:84-101.

2. Thorne C, Grabb WC, Ovid Technologies I. Grabb and Smith's Plastic Surgery, 6th edn. Philadelphia: London: Lippincott Williams \& Wilkins, 2007, Chapter 91.

3. Buncke HJ. Microvascular hand surgery-transplants and replants over the past 25 years. J Hand Surg (American Volume) 25;3:415-28.

4. Gulgonen A, Ozer K. Long-term results of major upper extremity replantations. T J Hand Sur Eur Vol 2011;37E:225-32.

5. Meyer VE. 2003. Upper extremity replantation - a review. Eur Surg 2003;35:167-73.

6. Tamai S. Twenty years' experience of limb replantation - review of 293 upper extremity replants. J Hand Surg 1982;7:549.

7. Hausman MR, Masters], Panozzo A. Hand transplantation: Current status. Mount Sinai J Med 2003;70:148.

8. Horng Y, Lin MC, Feng C, Huang C, Wu H, Wang J. Responsiveness of the Michigan Hand Outcomes Questionnaire and the Disabilities of the Arm, Shoulder, and Hand Questionnaire in patients with hand injury. J Hand Surg 2010;35A 430-6.

9. Sugun TS, Ozaksar K, Ada S, et al. Long-term results of major upper extremity replantations. Acta Orthop Traumatol Turc 2009;43:206-13.

10. De Smet L. The DASH questionnaire and score in the evaluation of hand and wrist disorders. Acta Orthop Belg 2008;74:575-81.

11. Hudak PL, Amadio PC, Bombardier C. Development of an upper extremity outcome measure: The DASH (Disabilities of the Arm, Shoulder, and Hand). Am J Industr Med 1996;29:602-8.

12. Chung KC, Pillsbury MS, Walters MR, et al. Reliability and validity testing of the Michigan Hand Outcomes Questionnaire. J Hand Surg 1998;23A:575-87.

13. Dias JJ, Rajan RA, Thompson JR. Which questionnaire is best? The reliability, validity and ease of use of the patient evaluation measure, the Disabilities of the Arm, Shoulder and Hand and the Michigan Hand Outcome Measure. J Hand Surg Eur Vol 2008;33E:9-17.

14. Hoang-Kim A, Pegreffi F, Moroni A, et al. Measuring wrist and hand function: Common scales and checklists. Injury 2011;42:253-8.

15. Shauver MJ, Chung KC. The minimally clinically important difference of the Michigan Hand Outcomes questionnaire. J Hand Surg 2009;34A:509-14.

16. Waljee JF, Chung KC, Kim HM, et al. Validity and responsiveness of the Michigan Hand Questionnaire in patients with rheumatoid arthritis: A multicenter, international study. Arthr Care Res 2010;62:1569-77.

17. Crawford JR, Henry JD, Crombie C, et al. Brief report: Normative data for the HADS from a large non-clinical sample. $\mathrm{Br} \mathrm{J}$ Clin Psychol 2001;40:429-34.

18. Crawford JR, Garthwaite PH, Lawrie CJ, et al. A convenient method of obtaining percentile norms and accompanying interval have been possible only via multicentre, international collaboration, and with lengthy enrollment and follow-up periods.

\section{CONCLUSION}

Our results suggest that major upper extremity injuries and replantations have a significant impact on patients' long-term hand function, and may result in anxiety and depressive symptoms.

ACKNOWLEDGEMENTS: The authors acknowledge the offices of Drs A Dal Cin, MJ Cooper, J Bain, R Avram, S Martin and R Patterson for assisting in contacting patients for follow-up, and for providing clinic space for patient assessments.

DISCLOSURES: The authors have no financial disclosures or conflicts of interest to declare.

estimates for self-report mood scales (DASS, DASS-21, HADS, PANAS, and sAD). Br J Clin Psychol 2009;48:163-80.

19. Harter M, Reuter K, Gross-Hardt K, et al. Screening for anxiety, depressive and somatoform disorders in rehabilitation - validity of HADS and GHQ-12 in patients with musculoskeletal disease. Disabil Rehabil 2001;23:737-44.

20. Zigmond AS, Snaith RP. The Hospital Anxiety and Depression Scale. Acta Psychiatrica Scandinavica 1983;67:361-70.

21. Berger A, Millesi H. Functional results from replantation surgery: A five year report from the Viennese replantation team. Austral NZ J Surg 1980;50:244-7.

22. Kleinert HE, Jablon M, Tsai TM. An overview of replantation and results of 347 replants in 245 patients. J Trauma Acute Care Surg 1980;20:390-8.

23. Russell RC, O'Brien BM, Morrison WA, Pamamull G, MacLeod A. The late functional results of upper limb revascularization and replantation. J Hand Surg 1984;9:623-33.

24. Scott FA, Howar JW, Boswick JA Jr. Recovery of function following replantation and revascularization of amputated hand parts. J Trauma Acute Care Surg 1981;21:204-14.

25. Davidson J. 2004. A comparison of upper limb amputees and patients with upper limb injuries using the Disability of the Arm, Shoulder and Hand (DASH). Disabil Rehabil 2004;26:917-23.

26. Ostlie K, Franklin RJ, Dip Phys G, et al. Assessing physical function in adult acquired major upper-limb amputees by combining the Disabilities of the Arm, Shoulder and Hand (DASH) outcome questionnaire and clinical examination. Arch Phys Med Rehabil 2011;92:1636-45.

27. Friedrich JC, Poppler LH, Mack CD, et al. Epidemiology of upper extremity replantation surgery in the United States. J Hand Surg 2011;36A:1835-40.

28. Laing TA, Cassell O, O'Donovan D, et al. Long term functional results from major limb replantations. J Plast Reconstr Aesthet Surg 2012;65:931-4.

29. Raja Sabapathy S, Venkatramani H, Bharathi RR, et al. Technical considerations and functional outcome of 22 major replantations. J Hand Surg Eur Vol 2007;32E:488-501.

30. Daoutis NK, Gerostathopoulos N, Efstathopoulos et al. Major amputation of the upper extremity: Functional results after replantation/revacularization in 47 cases. Acta Orthop Scand 1995;S264:7-8.

31. Paletta FX. Replantation of the amputated extremity. Ann Surg 1968;168:720-6.

32. Hoang NT, Hai LH, Staudenmaier R, et al. Complete middle forearm amputations after avulsion injuries - microsurgical replantation results in Vietnamese patients. J Trauma 2009;66:1167-72.

33. Pederson WC. CME: Replantation. Plast Reconstr Surg 2001;107:823-41. 